Article

\title{
A Systematic Review of Performance Analysis in Rowing Using Inertial Sensors
}

\author{
Matthew TO Worsey ${ }^{(}$, Hugo G Espinosa * $\mathbb{C}^{-}$, Jonathan B Shepherd $(\mathbb{C}$ and David V Thiel $\mathbb{C}$ \\ School of Engineering and Built Environment, Griffith University, Brisbane, QLD 4111, Australia; \\ matthew.worsey@griffithuni.edu.au (M.T.O.W.); j.shepherd@griffith.edu.au (J.B.S.); \\ d.thiel@griffith.edu.au (D.V.T.) \\ * Correspondence: h.espinosa@griffith.edu.au; Tel.: +61-7-3735-8432
}

Received: 22 October 2019; Accepted: 5 November 2019; Published: 7 November 2019

check for updates

\begin{abstract}
Sporting organizations such as professional clubs and national sport institutions are constantly seeking novel training methodologies in an attempt to give their athletes a cutting edge. The advent of microelectromechanical systems (MEMS) has facilitated the integration of small, unobtrusive wearable inertial sensors into many coaches' training regimes. There is an emerging trend to use inertial sensors for performance monitoring in rowing; however, the use and selection of the sensor used has not been appropriately reviewed. Previous literature assessed the sampling frequency, position, and fixing of the sensor; however, properties such as the sensor operating ranges, data processing algorithms, and validation technology are left unevaluated. To address this gap, a systematic literature review on rowing performance monitoring using inertial-magnetic sensors was conducted. A total of 36 records were included for review, demonstrating that inertial measurements were predominantly used for measuring stroke quality and the sensors were used to instrument equipment rather than the athlete. The methodology for both selecting and implementing technology appeared ad hoc, with no guidelines for appropriate analysis of the results. This review summarizes a framework of best practice for selecting and implementing inertial sensor technology for monitoring rowing performance. It is envisaged that this review will act as a guide for future research into applying technology to rowing.
\end{abstract}

Keywords: rowing; technology; inertial sensor; accelerometer; performance; signal processing

\section{Introduction}

Recent advances in technological developments have enabled the mass production of small, unobtrusive wearable inertial sensors [1]. These sensors can be used to directly monitor an athlete's biomechanics as well as to instrument the equipment an athlete interacts with in a laboratory, training, or competitive setting. Previous studies using wearable inertial sensors for athlete performance analysis show the hindrance of normal movement to be minimal [2]. The miniaturisation of inertial sensors is attributable to microelectromechanical systems (MEMS). MEMS are chip-level devices based on movement of silicon-based arms acting as a mass and spring. The acceleration and rotation can be logged and transmitted [3-5]. MEMS accelerometer technologies include those based on capacitive, piezoelectric, and piezoresistive effects [3]. When inertial sensors are used in rowing, the device must be waterproof. Moreover, if an athlete is being monitored on-water training, then other technologies such as global positioning system (GPS) and on-board video are recommended so that the inertial sensor data can be synchronised. 
This review outlines the published literature to assess the applications of inertial sensors in rowing. From this, athletes and coaches have a guide for inertial sensors applications and design method for implementations.

A systematic review evaluating the integration of wearable inertial sensors into a sporting environment for performance monitoring was published in March 2018 [6]. The review captured 286 records and of these 10/286 (3.50\%) included on-boat water sports such as rowing and kayaking. These relatively few records either show that there is a gap in using MEMS in performance monitoring in rowing or this is an under researched area. Due to the physically demanding and technical nature of rowing, it is hypothesized that performance monitoring tools would be of great benefit.

Reviews of scientific literature pertinent to rowing have been published; however, to the best of our knowledge, none have focused on the use of technology. Previous literature reviews in rowing have focused on the biomechanical and metabolic factors imperative for a successful rower and the likely injures to rowers. Baudouin and Hawkins [7] looked to bridge the gap between physiological, biomechanics and physical aspects involved in rowing by understanding the interrelationship between the biological and mechanical systems. They propose that the blade force is the only propulsive force counter-acting the drag forces (air drag and hydrodynamic drag acting on the rowing system. It was found that the impact of vertical oscillations of the shell are minimal. The link between blade force and the rower is the oar and this force is transmitted via the oarlock. They suggest that sustainable power is maximized through matching the rigging setup and blade design to the rower's joint torque-velocity characteristics. They concluded that a more comprehensive understanding of force-time profiles are needed so that deficiencies in a rower's biomechanics can be optimised to achieve greater force generation.

Michael et al. [8] reviewed literature surrounding the metabolic demands of kayaking. The scientific literature highlights the high levels of both aerobic power and anaerobic capacity across kayak athletes. They suggested that velocity of the kayak as well as force, power, technique and aerobic fitness are valuable metrics for athlete performance monitoring. Understanding the physiological demands of kayaking is a useful tool for coaches as it helps them make informed decisions about an athlete's suitability for race distances. It also helps to optimise training regimes to improve the performance of specific athletes.

Thornton et al. [9] evaluated published material focused on injuries in rowing. This review was updated in 2016 as rowing specific injury research has increased over the last decade. Key points found from the review were that the largest risk factor for rowing injury were rapid increases in training frequency, intensity and/or volume, appropriate loading in the boat and on a rowing ergometer can reduce the likeliness of overuse injuries, and, finally, there is still a significant demand for well-designed prospective studies focused on rowing injuries. It is evident that an athlete's rowing performance and likelihood of injury can possibly be quantified by metrics obtained via inertial sensors.

The previous literature reviews on rowing do not address the technology and methodologies used in rowing research. Without a framework, ad hoc methodologies concerning the selection and implementation of wearable technologies could reduce the accuracy and validity of rowing sport performance measures $[3,10]$.

\section{Materials and Methods}

A systematic review of literature was conducted (current as of 24 April 2019) using a methodology based on PRISMA (Preferred Reporting Items for Systematic Reviews and Meta-Analyses) recommendations for completing and reporting the findings of systematic reviews [11]. An electronic database search was completed in total of six relevant scholarly databases (Google Scholar, Web of 
Science (core collection), ProQuest, Scopus, Sage Journals and Science Direct) using the keywords identified in Table 1. Exclusion criteria meant manuscripts were only included in the final review if they satisfied the following: It must be a methods-based research article from a scholarly journal (available in English), which contains the use of inertial sensors and have a relevance to human performance monitoring in a rowing setting.

Table 1. Searched databases and associated search terms used, IMU (Inertial Measurement Unit).

\begin{tabular}{|c|c|}
\hline Database & Search Terms \\
\hline Web of Science (core collection) & $\begin{array}{c}\mathrm{TS}=(\text { Rowing AND sport AND (Inertial sensors OR Accelerometer } \\
\text { OR IMU) })\end{array}$ \\
\hline Scopus & $\begin{array}{c}\text { TITLE-ABS-KEY ((“Rowing” AND sport AND (“Inertial Sensors” } \\
\text { OR “Accelerometer" OR “IMU)) }\end{array}$ \\
\hline ProQuest & $\begin{array}{c}\text { ALL ("Rowing" AND sport AND ("Inertial Sensors" } \\
\text { OR “Accelerometer" OR "IMU)) }\end{array}$ \\
\hline Science Direct & ("Rowing") AND "sport" AND ("Inertial Sensors" OR \\
\hline Sage Journals & $\begin{array}{c}\text { Anywhere ("Rowing") AND anywhere (sport) AND } \\
\text { anywhere ("Inertial Sensors" OR "Accelerometer" OR "IMU") }\end{array}$ \\
\hline Google Scholar & Rowing, OR Sport, OR IMU, OR Inertial OR Sensor, OR Accelerometer \\
\hline
\end{tabular}

The included papers were reviewed on the following: (i) the geographical location of where the study was conducted; (ii) properties of the inertial sensor used in the study; (iii) the placement of the inertial sensor in the study; (iv) what algorithms were used for data processing; (v) what performance features were analysed; (vi) study design, and (vii) whether other validated technologies/procedures were implemented to ensure accuracy and validity of the investigation. The record screening process is shown in Figure 1.

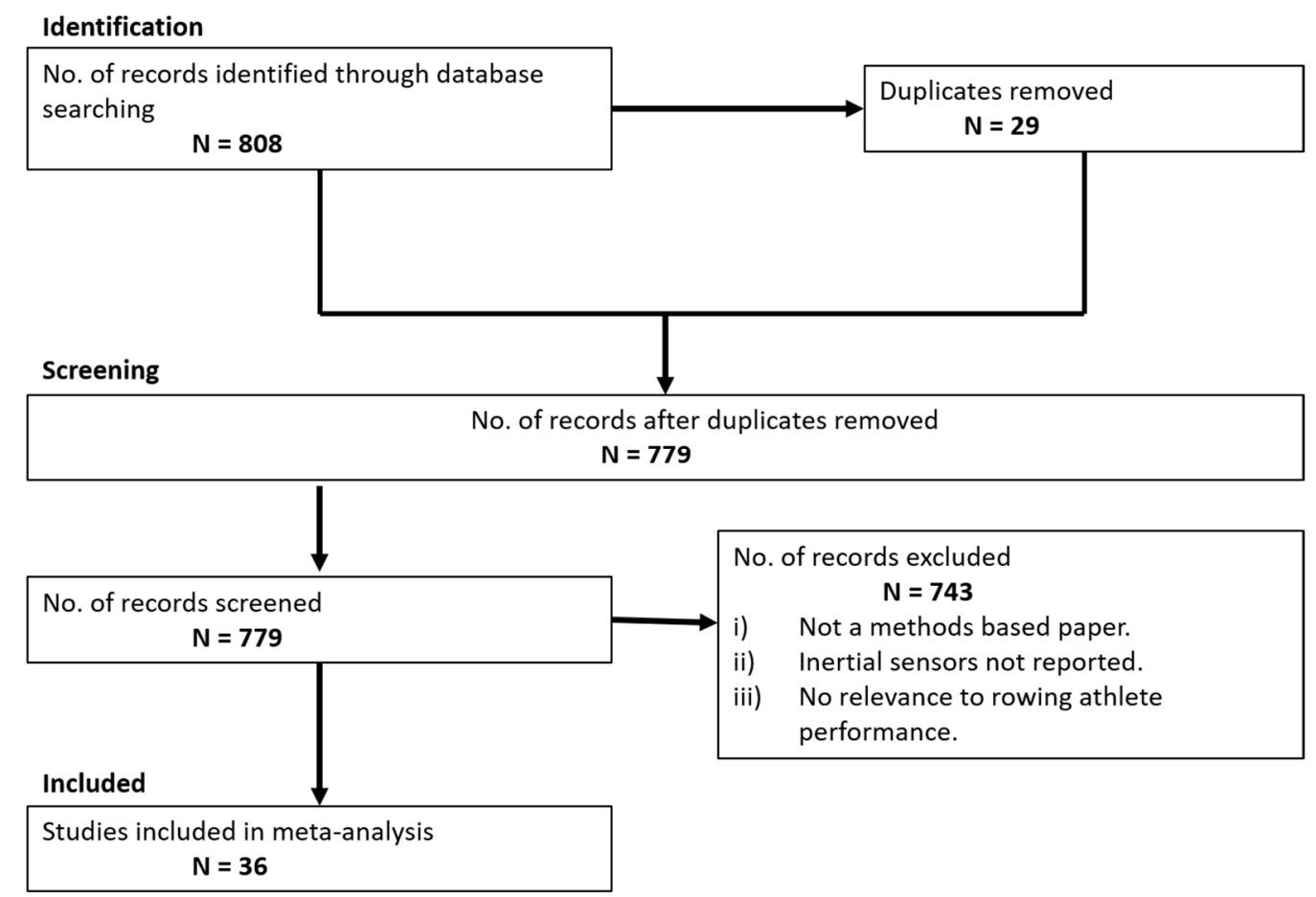

Figure 1. Flow diagram of study selection. 


\section{Results}

\subsection{Journals and Years}

The papers included in the systematic review were published in several scientific journals. The journals could be divided into three fields of research: Engineering and Technology (78.0\%), Sport Science and Medicine (14.0\%) and Biomechanics (8.0\%) (Figure 2a). The number of papers published each year since 2004 is shown in Figure $2 b$.

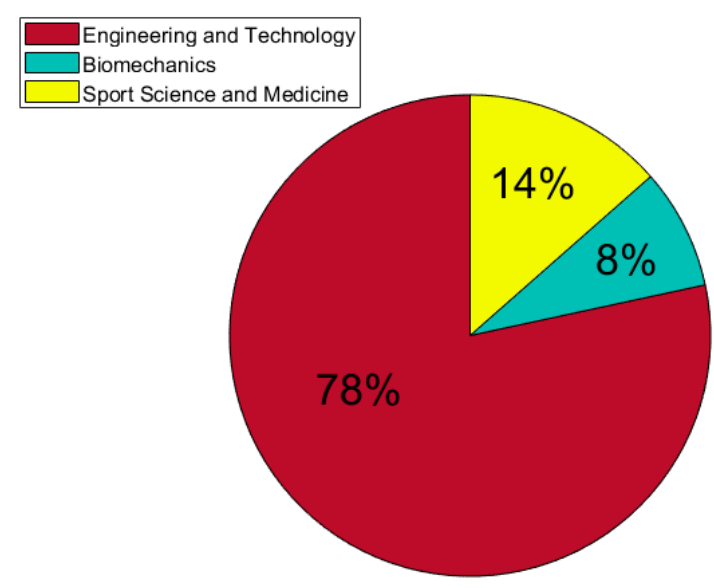

(a)

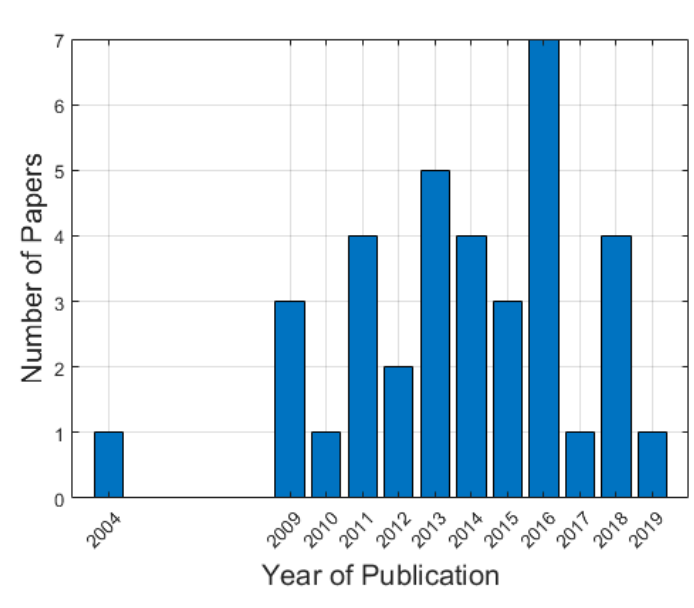

(b)

Figure 2. (a) journal distribution; (b) publication frequency by year. The total number of papers since 2004 is 35.

\subsection{Performance Features}

An athlete's overall performance in rowing is dependent on many factors. Rowing is an interesting sport to analyse as it has to be considered a system controlled by athlete-equipment interaction. The performance features that were examined in the captured articles were extracted (Table 2). Ultimately, the most important factor for performance in rowing is boat velocity; however, this metric is influenced by various inputs. The features were divided into four main groups: stroke quality, instrumented material metrics, athlete physicality/physiology metrics, and general biofeedback. The stroke quality group consists of metrics such as stroke length, stroke rate, recovery/drive phase ratio, stroke variance, stroke force, and cadence. By instrumenting the equipment used by the athlete, many measures of performance can be observed. Instrumented material metrics included boat position, boat velocity, foot-rest force, boat orientation, oar orientation, and stability. Rowing is an extremely physically demanding sport and requires high skill and therefore the physical and physiological makeup of the athlete is also vital. In this group, measures associated with fatigue, power output, muscle activity, energy output, and also crew synchronicity for team rowing. Finally, general feedback consisted of split times and activity classification.

\subsection{Data Processing Algorithms}

Various techniques can be used for signal processing of time-series data, for example, frequency filtering of data to remove the effect of noise or drift. Time-series data can also be transferred to the frequency domain using Fourier transforms enabling frequency analysis. Machine learning and deep learning techniques can also be applied for automatic classification of significant events in rowing or human actions, summarized in Table 3. It should be noted that some of the included records used commercialized measurement technology and so limited information about the data processing methods is available. 


\subsection{Study Design and Hardware}

The included records were also reviewed with respect to their study design and the properties of the inertial sensor hardware used. The methodology was evaluated on the number of inertial sensor devices used, the sampling frequency and operating range of the sensors, the location of the device(s), data transmission, the testing environment, and participant selection (Tables 4 and 5). For studies testing the performance of novel hardware or extracting innovative metrics to assess an athlete's performance, then it is important to verify the measurements obtained with a measurements from a 'golden' standard technology. This ensures validity and reproducibility of the measurements obtained (Table 6). In sport and biomechanics research, the golden standard is commonly a multi-camera retro-reflective motion capture system that can track human positions in three-dimensional space. From this data, the acceleration and rotation of the body part can be calculated and compared to inertial sensor data [3]. The competitive setting for rowing is on-water and thus retro-reflective motion capture is not a viable option. It is recommended that measurements are made on a rowing ergometer in a laboratory environment initially. Despite the obvious differences in the biomechanical processes of an athlete when transferring from an ergometer to a scull, it will provide a baseline measurement with golden standard data to validate against.

Table 2. Rowing performance features.

\begin{tabular}{|c|c|c|c|c|c|}
\hline Citation & Sport & $\begin{array}{l}\text { Stroke } \\
\text { Quality }\end{array}$ & $\begin{array}{c}\text { Instrumented } \\
\text { Material } \\
\text { Metrics }\end{array}$ & $\begin{array}{c}\text { Athlete } \\
\text { Physicality/Physiology } \\
\text { Metrics }\end{array}$ & $\begin{array}{c}\text { General } \\
\text { Biofeedback }\end{array}$ \\
\hline [12] & Rowing & $\checkmark$ & $x$ & $v$ & $x$ \\
\hline [13] & Rowing & $\checkmark$ & $x$ & $x$ & $x$ \\
\hline [14] & Rowing & $\checkmark$ & $x$ & $\checkmark$ & $\times$ \\
\hline [15] & Rowing & $x$ & $x$ & $x$ & $\times$ \\
\hline [16] & Rowing & $v$ & $x$ & $\times$ & $v$ \\
\hline [17] & Rowing & $x$ & $x$ & $v$ & $\checkmark$ \\
\hline [18] & Rowing & $\times$ & $\nu$ & $x$ & $x$ \\
\hline [19] & Rowing & $\checkmark$ & $x$ & $x$ & $x$ \\
\hline [20] & Rowing & $x$ & $x$ & $\checkmark$ & $x$ \\
\hline [21] & Rowing & $\checkmark$ & $x$ & $x$ & $x$ \\
\hline [22] & Rowing & $\checkmark$ & $x$ & $x$ & $x$ \\
\hline [23] & Rowing & $x$ & $x$ & $x$ & $x$ \\
\hline [24] & Rowing & $x$ & $x$ & $x$ & $x$ \\
\hline [25] & Rowing & $\checkmark$ & $\checkmark$ & $\times$ & $x$ \\
\hline [26] & Kayaking & $\checkmark$ & $\checkmark$ & $x$ & $x$ \\
\hline [27] & Rowing & $\checkmark$ & $x$ & $\times$ & $x$ \\
\hline [28] & Rowing & $x$ & $x$ & $v$ & $x$ \\
\hline [29] & Rowing & $v$ & $x$ & $x$ & $x$ \\
\hline [30] & Rowing & $v$ & $\times$ & $\times$ & $x$ \\
\hline [31] & Rowing & $v$ & $\checkmark$ & $x$ & $x$ \\
\hline [32] & Rowing & $v$ & $x$ & $\nu$ & $\times$ \\
\hline [33] & Rowing & $v$ & $x$ & $x$ & $v$ \\
\hline [34] & Rowing & $v$ & $\checkmark$ & $x$ & $x$ \\
\hline [35] & Kayaking & $\checkmark$ & $\checkmark$ & $x$ & $\times$ \\
\hline [36] & Canoeing & $\checkmark$ & $\checkmark$ & $x$ & $x$ \\
\hline [37] & Kayaking/Canoeing & $\checkmark$ & $\checkmark$ & $x$ & $x$ \\
\hline [38] & Rowing & $\checkmark$ & $x$ & $x$ & $x$ \\
\hline [39] & Rowing & $x$ & $\checkmark$ & $x$ & $\times$ \\
\hline [40] & Rowing & $\times$ & $x$ & $x$ & $\times$ \\
\hline [41] & Rowing & $x$ & $x$ & $x$ & $x$ \\
\hline [42] & Canoeing & $\checkmark$ & $x$ & $x$ & $x$ \\
\hline [43] & Rowing & $x$ & $\times$ & $\checkmark$ & $x$ \\
\hline [44] & Rowing & $\checkmark$ & $\checkmark$ & $x$ & $x$ \\
\hline [45] & Rowing & $x$ & $\checkmark$ & $x$ & $x$ \\
\hline [46] & Rowing & $\checkmark$ & $\boldsymbol{v}$ & $x$ & $x$ \\
\hline [47] & Rowing & $\checkmark$ & $\checkmark$ & $x$ & $\times$ \\
\hline
\end{tabular}


Table 3. Signal processing algorithms used on data, KNN (K-nearest Neighbours); DTW (Dynamic Time Warping); SVM (Support Vector Machine).

\begin{tabular}{|c|c|c|c|c|}
\hline Citation & Sport & Filtering/Windowing Data & Fourier Transform (Frequency Analysis) & Machine/Deep Learning Techniques \\
\hline [12] & Rowing & $x$ & $x$ & $x$ \\
\hline [13] & Rowing & $x$ & $x$ & $x$ \\
\hline [14] & Rowing & $v$ & $x$ & $x$ \\
\hline [15] & Rowing & $x$ & $x$ & $x$ \\
\hline [16] & Rowing & $x$ & $x$ & \\
\hline [17] & Rowing & $x$ & $v$ & KNN \\
\hline [18] & Rowing & $\hat{v}$ & $\checkmark$ & $\times$ \\
\hline [19] & Rowing & $x$ & $x$ & $x$ \\
\hline [20] & Rowing & $x$ & $x$ & $x$ \\
\hline [21] & Rowing & $x$ & $x$ & $x$ \\
\hline [22] & Rowing & $\hat{v}$ & $x$ & KNN \\
\hline [23] & Rowing & $x$ & $x$ & $\times$ \\
\hline [24] & Rowing & $x$ & $x$ & $x$ \\
\hline [25] & Rowing & $x$ & $x$ & DTW \\
\hline [26] & Kayaking & $v$ & $x$ & $\times$ \\
\hline [27] & Rowing & $v$ & $x$ & $x$ \\
\hline [28] & Rowing & $x$ & $x$ & $x$ \\
\hline [29] & Rowing & $x$ & $x$ & $x$ \\
\hline [30] & Rowing & $v$ & $x$ & $x$ \\
\hline [31] & Rowing & $x$ & $x$ & $x$ \\
\hline [32] & Rowing & $x$ & $x$ & $x$ \\
\hline [33] & Rowing & $x$ & $x$ & $x$ \\
\hline [34] & Rowing & $v$ & $x$ & $x$ \\
\hline [35] & Kayaking & $x$ & $x$ & $x$ \\
\hline [36] & Canoeing & $x$ & $x$ & $x$ \\
\hline [37] & Kayaking/Canoeing & $x$ & $x$ & $x$ \\
\hline [38] & Rowing & $v$ & $x$ & $x$ \\
\hline [39] & Rowing & 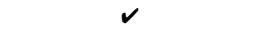 & $x$ & $x$ \\
\hline [40] & Rowing & $v$ & $x$ & $x$ \\
\hline [41] & Rowing & $v$ & $x$ & \\
\hline [42] & Canoeing & $v$ & $x$ & SVM \\
\hline [43] & Rowing & $v$ & $x$ & $x$ \\
\hline [44] & Rowing & $v$ & $x$ & $x$ \\
\hline [45] & Rowing & $x$ & $x$ & $x$ \\
\hline [46] & Rowing & $x$ & $x$ & $x$ \\
\hline [47] & Rowing & $v$ & $x$ & $x$ \\
\hline
\end{tabular}

Table 4. Properties of inertial sensor instrumentation, Number (\#) of devices; OR (Operating Range); RF (Radio Frequency); BT (Bluetooth); ANT (Adaptive network technology); NS (Not Stated); NA (Not Applicable).

\begin{tabular}{|c|c|c|c|c|c|c|c|}
\hline Citation & Sport & \# of Devices & Accelerometer OR & Gyroscope OR & Magnetometer OR & $\begin{array}{l}\text { Sampling } \\
\text { Frequency }\end{array}$ & Transmission \\
\hline [12] & Rowing & 3 & NS & NS & NS & NS & RF \\
\hline [13] & Rowing & 2 & NS & NS & NS & NS & $\mathrm{RF}$ \\
\hline [14] & Rowing & 1x each athlete & $\pm 16 \mathrm{~g}$ & $\pm 2000^{\circ} / \mathrm{s}$ & \pm 49 Gauss & $100 \mathrm{~Hz}$ & BT/local \\
\hline [15] & Rowing & 1 & NS & NA & NA & $100 \mathrm{~Hz}$ & NS \\
\hline [16] & Rowing & 3 & $\pm 6 \mathrm{~g}$ & NA & NA & $120 \mathrm{~Hz}$ & BT \\
\hline [17] & Rowing & 1 & $\pm 3 \mathrm{~g}$ & NA & NA & $50 \mathrm{~Hz}$ & RF \\
\hline [18] & Rowing & 3 & $\pm 6 \mathrm{~g}$ & NA & NA & $83 \mathrm{~Hz}$ & RF \\
\hline [19] & Rowing & 1 & $\pm 10 \mathrm{~g}$ & NA & NA & $250 \mathrm{~Hz}$ & NS \\
\hline [20] & Rowing & 18 & $\pm 16 \mathrm{~g}$ & $\pm 2000^{\circ} / \mathrm{s}$ & \pm 1.9 Gauss & $\begin{array}{l}240 \mathrm{~Hz} \text { wired/ } \\
60 \mathrm{~Hz} \text { wireless }\end{array}$ & Real Time \\
\hline [21] & Rowing & 3 & NS & $\pm 900^{\circ} / \mathrm{s}$ & NS & NS & Wired \\
\hline [22] & Rowing & 3 & $\pm 6 \mathrm{~g}$ & $\pm 2000^{\circ} / \mathrm{s}$ & NS & $200 \mathrm{~Hz}$ & RF \\
\hline [23] & Rowing & 2 & $> \pm 4.2 \mathrm{~g}$ & NA & NA & NS & Wireless 802.15 .4 \\
\hline [24] & Rowing & 1 & NS & NA & NA & NS & $\mathrm{RF}$ \\
\hline [25] & Rowing & 1 & $\pm 3 \mathrm{~g}$ & NA & NA & $50 \mathrm{~Hz}$ & NS \\
\hline [26] & Kayaking & $2 x$ each athlete & NS & NA & NA & NS & RF \\
\hline [27] & Rowing & 1 & $\pm 16 \mathrm{~g}$ (scalable) & $\pm 2000^{\circ} / \mathrm{s}$ & NA & $200 \mathrm{~Hz}$ & Local (SD card) \\
\hline [28] & Rowing & 1 & $\pm 2 \mathrm{~g}$ & NA & NA & NS & RF \\
\hline [29] & Rowing & 2 & $\pm 5 \mathrm{~g}$ & NA & NA & NS & NS \\
\hline [30] & Rowing & 1 & NS & NS & NS & NS & Wireless \\
\hline [31] & Rowing & 1 & NS & NA & NA & $25 \mathrm{~Hz}$ & RF \\
\hline [32] & Rowing & 1 & $\pm 8 \mathrm{~g}$ (scalable) & NA & NA & $\geq 125 \mathrm{~Hz}$ & NS \\
\hline [33] & Rowing & 5 & $\pm 16 \mathrm{~g}$ (scalable) & $\pm 2000^{\circ} / \mathrm{s}$ (scalable) & \pm 12 Gauss & $100 \mathrm{~Hz}$ & BT \\
\hline [34] & Rowing & 1 & $\pm 2 \mathrm{~g}$ & NA & NA & $50 \mathrm{~Hz}$ & Wi-Fi \\
\hline [35] & Kayaking & 2 & $\pm 16 \mathrm{~g}$ & $\pm 2000^{\circ} / \mathrm{s}$ & NA & $50 \mathrm{~Hz}$ & BT \\
\hline [36] & Canoeing & 1 & NS & NS & NS & NS & NS \\
\hline [37] & Kayaking/Canoeing & 3 & NS & NS & NS & NS & NS \\
\hline [38] & Rowing & 1 & $\pm 2 \mathrm{~g}$ & NA & NA & $50 \mathrm{~Hz}$ & Wi-Fi \\
\hline [39] & Rowing & 1 & NS & NA & NA & $100 \mathrm{~Hz}$ & Real Time \\
\hline [40] & Rowing & 3 & $\pm 16 \mathrm{~g}$ & $\pm 2000^{\circ} / \mathrm{s}$ & \pm 8 Gauss & $100 \mathrm{~Hz}$ & RF \\
\hline [41] & Rowing & 3 & $\pm 3 \mathrm{~g}$ & $\pm 500^{\circ} / \mathrm{s}$ & NA & $50 \mathrm{~Hz}$ & RF \\
\hline [42] & Canoeing & 9 & $\pm 6 \mathrm{~g}$ & $\pm 500^{\circ} / \mathrm{s}$ & NA & $100 \mathrm{~Hz}$ & RF \\
\hline [43] & Rowing & 14 & $\pm 16 \mathrm{~g}$ & $\pm 2000^{\circ} / \mathrm{s}$ & \pm 1.9 Gauss & $60 \mathrm{~Hz}$ & Real Time \\
\hline [44] & Rowing & 1 & $\pm 6 \mathrm{~g}$ & $\pm 300^{\circ} / \mathrm{s}$ & NS & $50 \mathrm{~Hz}$ & NS \\
\hline [45] & Rowing & 2 & $\pm 6 \mathrm{~g}$ & $\pm 2000^{\circ} / \mathrm{s}$ & \pm 4 Gauss & $128 \mathrm{~Hz}$ & ANT+ \\
\hline [46] & Rowing & 1 & NS & NS & NS & $100 \mathrm{~Hz}$ & USB \\
\hline [47] & Rowing & 1 & $\pm 16 \mathrm{~g}$ & $\pm 2000^{\circ} / \mathrm{s}$ & \pm 8 Gauss & $100 \mathrm{~Hz}$ & BT/local/cloud \\
\hline
\end{tabular}


Table 5. Sensor placement, Erg (Ergometer); B (Boat).

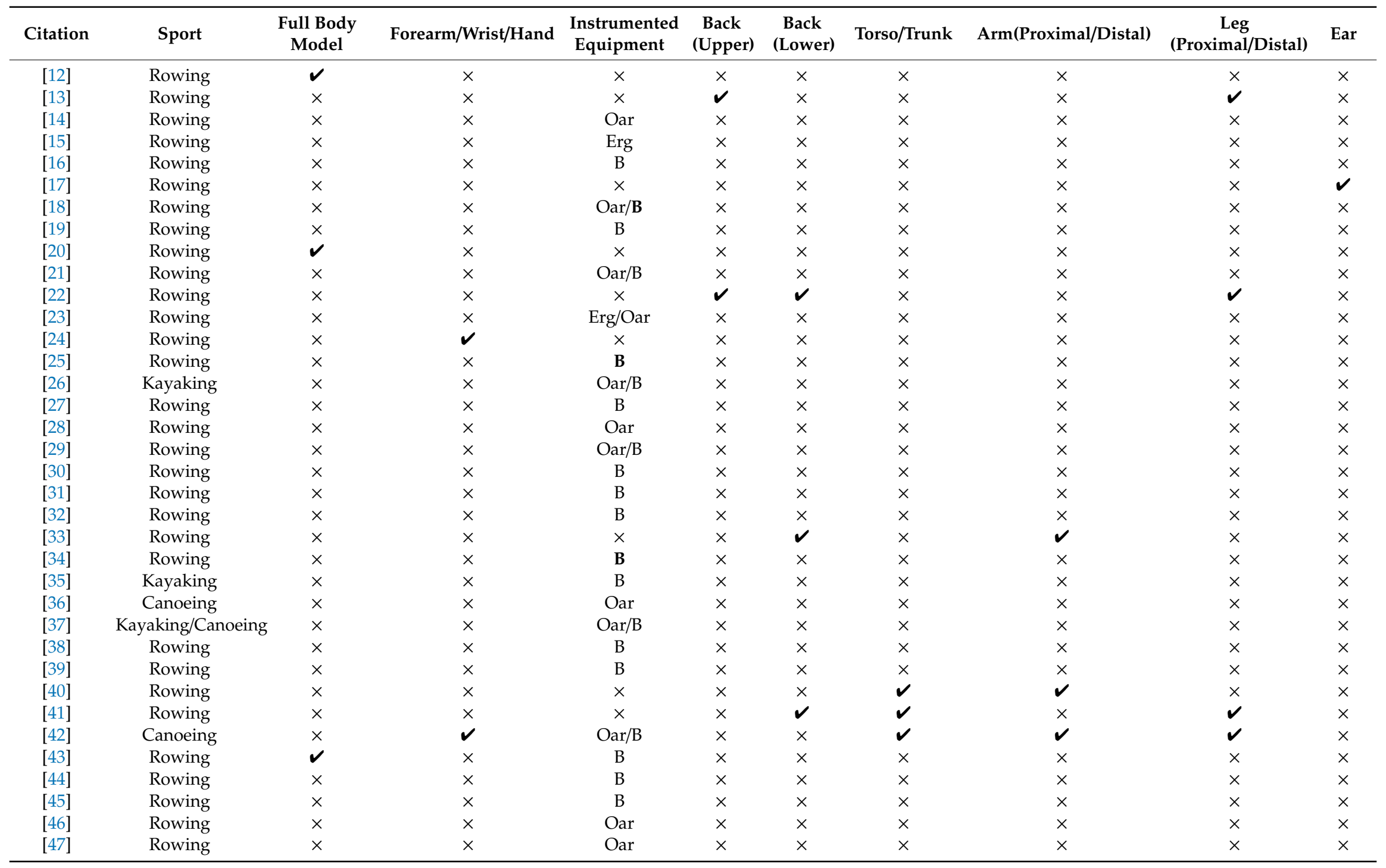


Table 6. Table of inertial sensor validation methods used in the included records.

\begin{tabular}{ccc}
\hline Citation & Sport & Validation Technology \\
\hline$[12]$ & Rowing & Optical motion capture \\
{$[14]$} & Rowing & Coach qualitative assessment \\
{$[17]$} & Rowing & Manual feature labelling \\
{$[18]$} & Rowing & Controlled laboratory validation test \\
{$[20]$} & Rowing & Force plates \\
{$[25]$} & Rowing & GPS \\
{$[27]$} & Rowing & GPS \\
{$[30]$} & Rowing & Navilock-550 ERS \\
{$[32]$} & Rowing & Optical motion capture \\
{$[33]$} & Rowing & GPS \\
{$[38]$} & Rowing & Optical motion capture \\
{$[39]$} & Rowing & Optical motion capture \\
{$[40]$} & Rowing & Video Camera \\
{$[41]$} & Rowing & GPS and stroke coach monitor \\
{$[42]$} & Canoeing & GPS \\
{$[43]$} & Rowing & Peach innovations measurement oarlock \\
{$[44]$} & Rowing & Rowing
\end{tabular}

\section{Discussion}

\subsection{General Trends}

Recent technological developments have made wearable inertial sensors readily available. This has led to sport coaches integrating these devices into their training routines to obtain more measures of an athlete's sport performance in real time [48]. This review highlighted three major research disciplines that are implementing inertial sensors into a rowing setting. These are Biomechanics $(n=3)$, Sport Science and Medicine $(n=5)$, and Engineering and Technology $(n=28)$. The increased availability of inertial sensors is reflected by the rapid increase in the volume of research investigating the use of inertial sensors in rowing since 2004 (Figure 2b). There is a diverse geographic spread of rowing technology research. Countries such as Algeria, Australia, Canada, China, France, Germany, Greece, Italy, Malaysia, Netherlands, New Zealand, Portugal, Slovenia, Spain, Sweden, Switzerland, the United Kingdom, and the United States of America all reported the use of inertial sensors in rowing. The majority of research published originated from Italy $(16.7 \%)$. Italy won six gold medals at the U23 world championships that may demonstrate the value of integrating sport technology into athlete training programs [49].

\subsection{Performance Features}

Over half of the included records (24/36-66.7\%) used inertial sensors to monitor stroke quality. In rowing, the stroke is the most vital performance indicator and overall performance can be increased by either increasing the propulsive impulse or decreasing the drag impulse within a stroke cycle [7]. The ability to measure the quality of the stroke cycle with an abundance of metrics is thus of high interest to coaches and athletes alike. Stroke rate (cadence) was the most frequently extracted metric surrounding stroke quality $(12 / 24-50.0 \%)[14,16,21,25,26,33-37]$. Athletes can have an optimal stroke rate based on their physicality and thus it is an important metric to monitor. It can also be measured easily with correctly placed inertial sensors. Stroke variability was investigated by seven of the stroke quality concerned records $(7 / 24-29.2 \%)$. Stroke by stroke variation in the inertial signals can indicate when athletes are performing well or have faults in their biomechanical processes, stroke variance is also highly investigated in swimming [5]. Three records (3/24-12.5\%) addressed the different phases of a stroke, such as the recovery and drive and the ratio of these phases [21,31,32]. The drive/recovery 
phase ratio is generally used to describe an athlete's rhythm with beginners being advised to aim for 2:1 (drive: recovery). The rhythm of a rower can be directly impacted by increases and decreases in stroke rate; both of these parameters were measured simultaneously by Tessendorf et al. [21]. Stroke length was monitored in three of the included records (4/24-16.7\%) [21,26,46,47]. Stroke length is measured in terms of the angle the oar sweeps from catch to finish position. By obtaining measures of stroke length, a coach can tailor training schedules to ensure athletes are entering catch and finish phase of their strokes optimally.

Over a third of the included records (13/36-36.1\%) analysed metrics surrounding instrumented rowing materials. Six of the thirteen records investigating instrumented rowing materials $(6 / 13-46.2 \%)$ measured boat velocity $[25,26,34,35,39,43]$. Boat velocity is the most important performance indicator in rowing. GPS is widely accepted as an accurate method to measure boat velocity in rowing; however, the signal is prone to drop outs. Thus, inertial sensors are an appealing method to obtain boat velocity or to work in conjunction with GPS to provide data during periods of drop out. Using inertial sensors to measure velocity can prove to be challenging due to gravitational offsets and sensor drift. Rowing, like swimming, consists of repetitive movements, relatively constant orientation and linear directional movement, providing advantages to the signal processing steps needed to measure velocity $[5,50,51]$.

Five of the instrumented material records (5/13-38.5\%) used inertial sensors to measure movement of the oar through the water $[18,36,37,46,47]$. This can provide coaches and athletes with a visual representation of oar's position through the stroke cycle. This gives potential for a golden standard template of a stroke which enters the different stroke phases at the optimal times to be used as a standard that athletes with certain deficiencies try to replicate. Four of the records (4/13-30.1\%) used inertial sensors to monitor the boats position $[25,39,44,45]$, with one of these records investigating the seat position within the boat. Similar to velocity, position is often measured by GPS; nonetheless during drop outs, inertial sensors can assist in interpolation/extrapolation of the GPS data to continuously monitor boat position even when GPS signal drops out. It can also be used to measure stroke efficiency in terms of the distance the boat travels per each stroke. This investigation used an inertial sensor to measure the position of a sliding rowing boat seat. This movement is a direct result of the rower's leg movement and thus is key for optimizing performance. Deficiencies in leg movement of a rower can significantly decrease the velocity of the boat.

Akin to boat position, three of the records (3/13-23.1\%) used inertial sensors to monitor the orientation of the boat $[18,35,44]$. By fusing the sensors within an inertial sensor, typically an accelerometer and gyroscope sometimes accompanied by a magnetometer, an accurate estimation of orientation can be calculated. This is an important metric, as if the boat is deviating too much from its linear path then efficiency is decreased. Thus, athletes can focus on stabilization in their training routines if this is an issue.

Oar stroke force was also an instrumented material metric of interest with three of the records $(3 / 13-23.1 \%)$ investigating it. As mentioned earlier, performance in rowing is dependent on increasing propulsive impulse while decrease drag impulse in a stroke cycle [7]. The oar acts as the link between the forces developed by the rower to the blade and creates the propulsive force. Enabling coaches and athletes to measure accurately the oar stroke force is extremely advantageous as strength and conditioning programs can be prescribed to help increase the oar stroke force and in turn overall propulsion of the boat.

Seven of the reviewed papers $(7 / 36-19.4 \%)$ investigated rowing athletes' physiological and physicality parameters using inertial sensors. Four of these records (5/7-71.4\%) analysed crew synchronicity $[12,14,20,23,32]$. An elite rower has high special fitness; high coordination, motor control and functional strength [52]. As well as special fitness, team rowers also have to maintain boat stability while staying synchronised with their crew. High synchronicity has been related to increased performance as reflected by the average hull speed [23]. Thus, being able to use inertial sensor data as a measure of synchronicity between rowers can aid coaches in having a more informed understanding of their rowing crew's interactions during training and competition. Armstrong and 
Nokes [12] investigated synchronization through acceleration signatures and electromyography signals. This demonstrated the muscle recruitment requirements for different boat positions (stroke, bow). It was also clear to see in the EMG signal the difference between good rowing technique and rowing when 'shooting the slide', which is driving with the legs so the seat leads the back into the drive phase rather than leg and back drive acting as one phase. Two of the records $(2 / 7-28.6 \%)$ measured athletes' power output. Estimates of the angular rotation of the oar shaft were obtained using a fitted an accelerometer; the inertial sensors were used in conjunction with force sensors and thus, with the shaft's radius, torque could be derived. Power is the product of torque and angular rotation and can be calculated using an inertial sensor and force sensor. Being able to quantify power output in training and rehabilitation means coaches can monitor their athletes more thoroughly and ensure that their program is achieving efficient results. Atallah et al. [17] (1/7-14.3\%) used an earn worn sensor to classify activates and estimate energy output; this was a general study that incorporated rowing as one the activities. However, it does have the possibility to be used purely for rowing.

Three of the reviewed records $(3 / 36-8.3 \%)$ provided general biofeedback measures such as tracking the athletes body during rowing, evaluating different methods of providing sonification feedback to rowers and activity classification $[16,17,33]$.

\subsection{Algorithms}

In order to obtain relevant and insightful metrics from inertial sensor signals, signal processing algorithms have to be used. Presenting raw signal data to a coach or an athlete is sometimes inappropriate as distinct biomechanical events are not distinct; noise can be eradicated from a signal using correctly designed filters. A high volume of the reviewed papers used a windowing/filtering technique during their data analysis (15/36-41.7\%) [14,18,22,26,27,30,34,38-44,47].

Of the 15 records, nine $(9 / 15-60.0 \%)$ reported the use of a low pass filter $[14,18,26,27,30,34,38,39,43]$. Seven out of nine of the low pass filters (7/9-77.8\%) $[14,18,26,27,30,38,43]$ were used for noise removal. The majority of the noise removal low pass filters were Butterworth $(4 / 7-57.1 \%)[18,26,27,43]$ filters ranging from orders of $2-4$. The cut off frequencies used for the accelerometer signals ranged from $4 \mathrm{~Hz}-20 \mathrm{~Hz}[14,18,26,27,30,43]$, one record stated the use of a low pass 2nd order Butterworth filter on the gyroscope signal, which had a cut off frequency of $15 \mathrm{~Hz}$ [27]. One record used a windowed FIR filter for noise removal but did not state the cut off frequency [38].

Four of the reviewed papers $(4 / 15-26.7 \%)$ used sensor fusion algorithms for different purposes $[22,39,40,47]$. Of these, three-quarters $(3 / 4-75.0 \%)$ used sensor fusion computational algorithms to obtain the rower's orientation metrics (e.g., joint angles and oar angles) [22,40,47]. Using inertial sensors to obtain orientation data can produce insightful metrics. The golden standard for these types of biomechanical measures is optical motion capture. By combining anthropometric measurements with the angles obtained by inertial sensors, they can act as a cheaper alternative. Cloud et al. [39] evaluated different sensor fusion (accelerometer and GPS) methods for estimating rowing kinematics such as boat speed and distance travelled. Using the sensor fusion method, the accuracy for boat speed, boat distance travelled and distance per stroke were increased by $44 \%, 42 \%$ and $73 \%$, respectively, when compared to a single channel smartphone GPS.

Machine learning, neural networks and artificial intelligence (AI) algorithms are now frequently applied to sports data for usually time-consuming manual tasks such as feature labelling, classification and future events can be predicted based on existing data. By extracting relevant features in both the time and frequency domains, researchers can apply these algorithms to generate personalized athlete models to further understand their performance. Four of the reviewed records reported the use of these algorithms [17,22,25,42]. Atallah et al. [17] used a KNN model to classify different activities, whereby rowing was one (76.39\% success rate). Bosch et al. [22] also used a KNN technique, however, to use inertial sensor signals to distinguish between novice and experienced rowers. The researchers did this by comparing the signals obtained by both experienced and novice rowers to a template generated by an experienced rower. For the most part, the experienced rowers had a closer similarity to the 
reference rower. The authors concluded that machine learning techniques can distinguish between experienced and novice rowers; however, its hindrance is that it cannot tell the novice rower what their exact deficiency in technique is. Groh et al. [25] used DTW to predict velocity when a GPS signal drops out using inertial sensor data based on the last registered GPS velocity. Wang et al. [42] used SVM classifiers to automatically segment different human motion phases in canoeing; the algorithm was verified by synchronised video footage.

Only two records $(2 / 36-5.6 \%)$ analysed data in the frequency domain. Atallah et al. [17] extracted features from the frequency domain to enhance the accuracy of their machine learning model. Llosa et al. [18] used the frequency domain to make more informed decisions about the cut off frequency they used in their signal noise-filter.

\subsection{Hardware}

Table 4 presents the properties of the inertial sensors used in the 36 reviewed papers. Fourteen of the 36 records $(15 / 36-41.7 \%)$ used more than one sensor to make measurements. Seventeen of the 36 records (17/36-47.2\%) used an inertial sensor with a built-in accelerometer and gyroscope or magnetometer. Of these seventeen, four (4/17-23.5\%) only used an accelerometer and gyroscope and the remaining $13(13 / 17-76.5 \%)$ also incorporated a magnetometer. The highest reported accelerometer range was $\pm 16 \mathrm{~g}$ and the lowest was $\pm 2 \mathrm{~g}$. Compared to our laboratories, previous systematic literature review on the use of inertial sensors in combat sport [3], which reported a maximum and minimum operating range of $\pm 750 \mathrm{~g}$ and $\pm 8 \mathrm{~g}$, respectively, these ranges are low. Nonetheless, rowing is a sport that does not typically consist of high impact situations and thus $\pm 16 \mathrm{~g}$ and even $\pm 2 \mathrm{~g}$ should have a minute risk of sensor saturation.

The measurement devices' sampling frequencies ranged from $25 \mathrm{~Hz}$ to $250 \mathrm{~Hz}$, again, compared to combat sport these are low; however, the movement in rowing is far slower compared to strikes in combat sport. Typically, stroke rates in rowing range from 20 strokes per minute (SPM) to 40 SPM ( $2 / 3$ strokes per second) and thus even a sensor only recording 25 samples per second is going to record the motion with ease. The only concern is that a low sampling rate might only register one sample peaks and troughs, which can lead to underestimates of the true magnitude.

\subsection{Study Design}

Sensor placement, testing environment and the level of participant(s) in rowing was used to review the records in respect to their study design.

\subsubsection{Sensor Placement}

Table 5 describes the different sensor placements used across the 36 reviewed manuscripts. The majority of records instrumented a piece of the rowing equipment such as the boat, oars or ergometer with an inertial sensor (27/36-75.0\%). Instrumented equipment such as the oars were used to obtain measures such as stroke rate, boat orientation, stroke length, boat velocity, boat position and stability. When the athlete was instrumented, records recorded sensor placements on the forearm, back (upper/lower), torso, arm (proximal/distal), leg (proximal/distal) and ear. Two of the records also used full body inertial sensor systems. When athletes were instrumented, it was often to obtain measures of their body segment orientations throughout a stroke. It is clear, however, that the research community has focused more on instrumenting the rowing equipment with inertial sensors than the athlete and thus there are opportunities for future research investigations doing the latter.

\subsubsection{Study Environment}

The study environments were classified as either a laboratory/gym or on-water setting. The majority of studies were undertaken on-water (18/36-50.0\%) where-by two records had an initial controlled test in the laboratory initially and then used the same methodology on water. Fourteen of the records $(14 / 36-38.9 \%)$ conducted their investigations in a controlled laboratory environment, typically on a 
rowing ergometer; again, two of the records then transitioned the study to an on-water environment. The remaining four records did not report a study environment. It is promising to see that the majority of the studies have already been conducted in an on-water setting. The advantage of a laboratory setting is that a controlled study is easier to implement, and it offers availability of verification technology such as optical motion capture. Nonetheless, studies conducted in the actual competition environment provide more realistic data for coaching teams and athletes to base training programs around.

\subsubsection{Participant Selection}

Over half of the included records (19/36-52.8\%) recruited participants with experience in rowing. Notable participant recruitments included Olympic and national level rowers $[14,16,21,31,46]$. It is desirable to recruit participants of a high level within the researched sport as it produces data of higher reproducibility due to the athlete completing biomechanical processes with correct form. Nevertheless, recruiting participants of different levels can strengthen the robustness of machine learning algorithms, improving their accuracy for athletes and the general public. One record recruited novice rowers in order to create a machine learning algorithm which could decipher between experienced and unexperienced rowing techniques within the inertial sensor signals [22].

\subsection{Future Recommendations}

This review makes it known that stroke quality and instrumented material metrics are the most frequently assessed performance feature in rowing using inertial sensors. This is reflected by the sensor placements extracted from the included records; the majority of records instrumented a piece of rowing equipment. Future research should focus on instrumenting the rowing athlete as well as the equipment and finding an interrelationship between the two. This will help coaches identify faults within the rowing system as a whole.

Machine learning, neural network and AI algorithms are gaining momentum in the sport data field. This systematic review revealed that only four of the 36 records $(4 / 36-11.1 \%)$ implemented machine learning algorithms in rowing. Moreover, only two (2/36-5.6\%) transformed their data into the frequency domain. Further exploration of these two data processing techniques within the rowing technology field is warranted. Numerous included manuscripts used filtering/windowing processing techniques on their signal data. The majority of filters were used for noise removal and a minority used advanced sensor fusion techniques to calculate values of orientation. Using advanced sensor algorithms such as orientation filters can obtain more insightful metrics about the athlete and/or equipment they are using in terms of Euler Angles and Quaternions, allowing improved information quality and a more detailed assessment of performance.

The highest accelerometer operating range and sample rate reported were $\pm 16 \mathrm{~g}$ and $250 \mathrm{~Hz}$, respectively. Rowing is a low impact sport and subsequently an operating range of $\pm 16 \mathrm{~g}$ is acceptable with a low risk as of sensor clipping. MEMS technology is improving rapidly and inertial sensors with sampling frequencies $>1 \mathrm{kHz}$ are now readily available with improved sensor resolution. Therefore, it is recommended that future investigations could explore using higher sampling frequencies to improve the quality of the captured information.

\section{Operational Guidelines}

In similar fashion to the systematic review analyzing the use of inertial sensors in combat sport [3], there is currently no standardization for data collection and analysis procedures in rowing research. Therefore, operational guidelines in the form of a flowchart (Figure 3) and a table (Table 7) are proposed. These guidelines will assist researchers in the selection of technology (device properties, sensor position and validation technology) and data processing algorithms in future rowing technology investigations using inertial sensors. The guideline presented in this review is of the same nature as in the combat sport review as it can be generalized for technology implementation across different sports. 


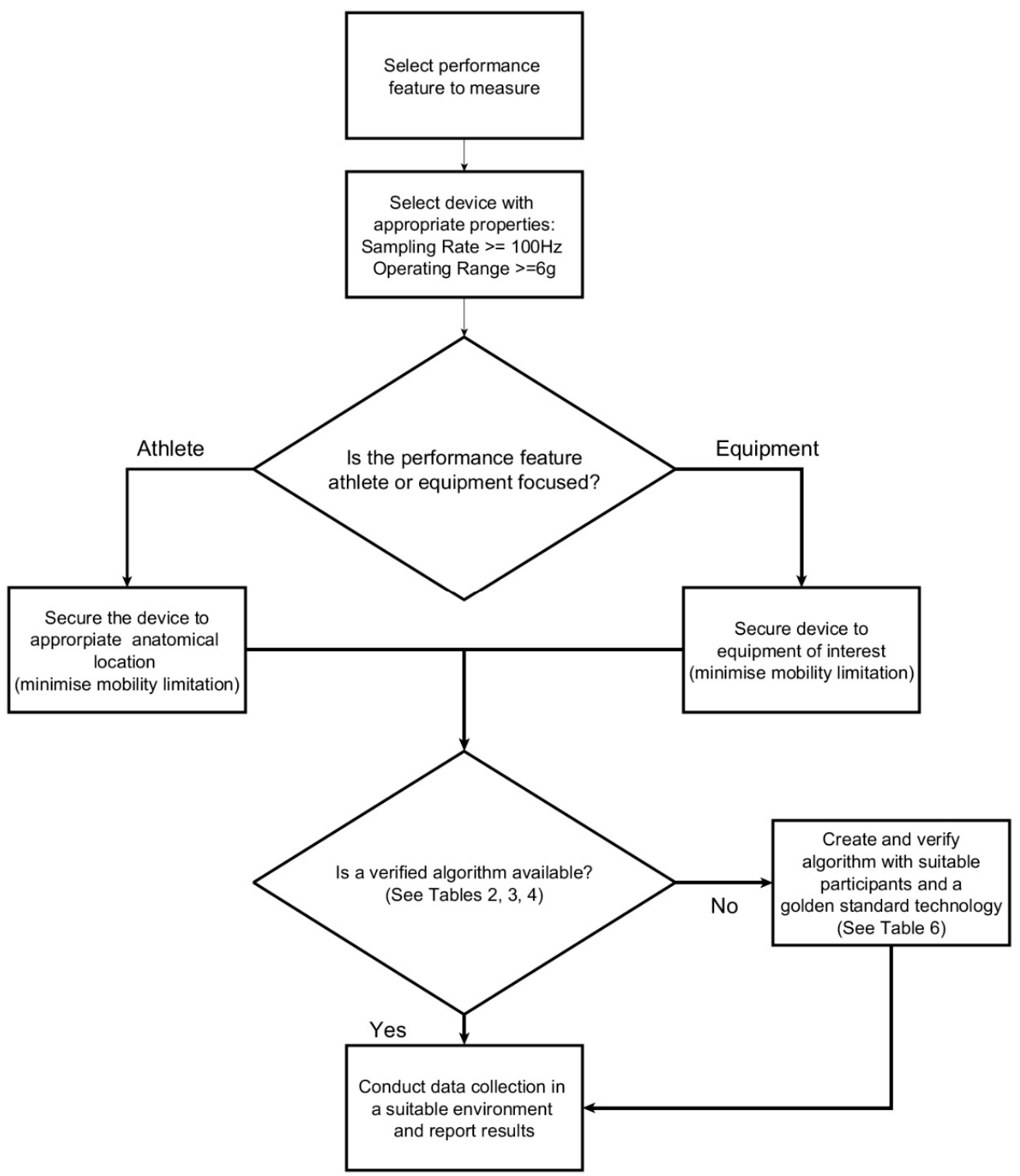

Figure 3. Operational guidelines for methodology design in rowing technology research.

Table 7. Reference guide for technology selection when conducting future research.

\begin{tabular}{|c|c|c|c|}
\hline Performance Feature & $\begin{array}{l}\text { Implementation } \\
\text { Complexity }\end{array}$ & $\begin{array}{l}\text { Minimum Hardware } \\
\text { Requirements }\end{array}$ & Minimum Algorithm Implementation \\
\hline $\begin{array}{c}\text { Stroke Quality: } \\
\text { Stroke phase ratios/Stroke } \\
\text { Length/Stroke Variance }\end{array}$ & $\begin{array}{l}\text { Intermediate to } \\
\text { Advanced }\end{array}$ & $\begin{array}{l}\text { Single IMU (on Oar), }>6 \mathrm{~g} \\
\text { Operating range, }>100 \mathrm{~Hz} \\
\text { Sampling Frequency }\end{array}$ & $\begin{array}{l}\text { Threshold peak detection } \\
\text { algorithm/advanced orientation } \\
\text { algorithm/statistical analysis for variance. }\end{array}$ \\
\hline $\begin{array}{l}\text { Instrumented Material Metrics: } \\
\text { Paddle stroke force/Stability/Boat } \\
\text { Position/Boat Velocity/Boat } \\
\text { Rotation/Oar Movement. }\end{array}$ & Advanced & $\begin{array}{l}\text { Single IMU (in different positions } \\
\text { depending on metric)), }>6 \mathrm{~g} \\
\text { Operating range, }>100 \mathrm{~Hz} \\
\text { Sampling Frequency }\end{array}$ & $\begin{array}{c}\text { Force output estimation } \\
\text { equation/Advanced orientation } \\
\text { algorithm/Machine learning } \\
\text { technique-calculus (w/GPS)/Machine } \\
\text { learning technique-calculus } \\
\text { (w/GPS)/Advanced orientation } \\
\text { algorithm/Advanced Orientation algorithm. }\end{array}$ \\
\hline $\begin{array}{l}\text { Athlete Physicality/Physiology: } \\
\text { Power output/Crew } \\
\text { Synchronization//Energy output }\end{array}$ & Intermediate & $\begin{array}{l}\text { Single IMU >6 g Operating range, } \\
>100 \mathrm{~Hz} \text { Sampling Frequency }\end{array}$ & $\begin{array}{c}\text { Power output estimation } \\
\text { equation/Correlation analysis/MET } \\
\text { estimation calculations }\end{array}$ \\
\hline $\begin{array}{l}\text { General Biofeedback: } \\
\text { Split times/Activity Classification. }\end{array}$ & $\begin{array}{l}\text { Simple to } \\
\text { Advanced }\end{array}$ & $\begin{array}{l}\text { Single IMU >6 g Operating range, } \\
>100 \mathrm{~Hz} \text { Sampling Frequency }\end{array}$ & $\begin{array}{l}\text { Threshold peak detection/machine } \\
\text { learning technique }\end{array}$ \\
\hline
\end{tabular}

Note-the minimum algorithm implementation for each different performance feature is separated by a/and correlates to the first column of the table. 


\section{Conclusions}

Inertial sensors can be used as a performance assessment tool in rowing. In the last decade, research into this field has gained momentum. Inertial sensors were used to measure performance features associated with stroke quality, metrics obtained from instrumented materials, indicators of the athlete's physicality and physiology and also general biofeedback. The review also assessed the properties of hardware that has been used in previous rowing research. Operational guidelines, based on this review, have been created and are proposed to assist future researchers with their methodology design and development. It is suggested that future research starts to incorporate more machine learning/neural network/AI algorithms and starts to focus on instrumenting the athlete rather than the equipment.

Author Contributions: Data retrieval, literature review design, review screening, and manuscript preparation, M.T.O.W.; literature review design, project supervision, and manuscript editing, H.G.E.; project supervision and manuscript editing, J.B.S. and D.V.T.

Funding: This research received no external funding.

Conflicts of Interest: The authors declare no conflict of interest.

\section{References}

1. Maenaka, K. MEMS inertial sensors and their applications. In Proceedings of the 2008 5th International Conference on Networked Sensing Systems, Kanazawa, Japan, 17-19 June 2008; IEEE: Kanazawa, Japan, 2008; pp. 71-73.

2. Shepherd, J.B.; Giblin, G.; Pepping, G.-J.; Thiel, D.; Rowlands, D. Development and validation of a single wrist mounted inertial sensor for biomechanical performance analysis of an elite netball shot. IEEE Sens. Lett. 2017, 1, 1-4. [CrossRef]

3. Worsey, M.; Espinosa, H.; Shepherd, J.; Thiel, D. Inertial sensors for performance analysis in combat sports: A systematic review. Sports 2019, 7, 28. [CrossRef]

4. Espinosa, H.G.; Lee, J.; James, D.A. The inertial sensor: A base platform for wider adoption in sports science and applications. J. Fit. Res. 2015, 4, 13-20.

5. Worsey, M.T.O.; Pahl, R.; Thiel, D.V.; Milburn, P.D. A comparison of computational methods to determine intrastroke velocity in swimming using IMUs. IEEE Sens. Lett. 2018, 2, 1-4. [CrossRef]

6. Camomilla, V.; Bergamini, E.; Fantozzi, S.; Vannozzi, G. Trends supporting the in-field use of wearable inertial sensors for sport performance evaluation: A systematic review. Sensors 2018, 18, 873. [CrossRef] [PubMed]

7. Baudouin, A. A biomechanical review of factors affecting rowing performance. Br. J. Sports Med. 2002, $36,396-402$.

8. Michael, J.S.; Rooney, K.B.; Smith, R. The metabolic demands of kayaking: A review. J. Sports Sci. Med. 2008, 7, 1.

9. Thornton, J.S.; Vinther, A.; Wilson, F.; Lebrun, C.M.; Wilkinson, M.; Di Ciacca, S.R.; Orlando, K.; Smoljanovic, T. Rowing Injuries: An Updated Review. Sports Med. 2017, 47, 641-661. [CrossRef]

10. Shepherd, J.B.; James, D.A.; Espinosa, H.G.; Thiel, D.V.; Rowlands, D.D. A literature review informing an operational guideline for inertial sensor propulsion measurement in wheelchair court sports. Sports 2018, 6, 34. [CrossRef]

11. Liberati, A.; Altman, D.G.; Tetzlaff, J.; Mulrow, C.; Gotzsche, P.C.; Ioannidis, J.P.A.; Clarke, M.; Devereaux, P.J.; Kleijnen, J.; Moher, D. The PRISMA statement for reporting systematic reviews and meta-analyses of studies that evaluate healthcare interventions: Explanation and elaboration. BMJ 2009, 339, b2700. [CrossRef]

12. Armstrong, S.; Nokes, L.D. Sensor node acceleration signatures and electromyography in synchronisation and sequencing analysis in sports: A rowing perspective. Proc. Inst. Mech. Eng. Part P J. Sports Eng. Technol. 2016, 231, 253-261. [CrossRef]

13. Safiee, M.S.; Ahmad, A.; Tukiran, Z.; Roslan, M.F.; Nadzri, M.M.M. Design and implementation of real-time rowing simulator (ReTRoS) for high-performance and low-injury-A preliminary work. In Proceedings of the 2016 IEEE EMBS Conference on Biomedical Engineering and Sciences (IECBES), Kuala Lumpur, Malaysia, 4-7 December 2016; IEEE: Kuala Lumpur, Malaysia, 2016; pp. 415-419. 
14. Avvenuti, M.; Cesarini, D.; Cimino, M. MARS, a multi-agent system for assessing rowers' coordination via motion-based stigmergy. Sensors 2013, 13, 12218-12243. [CrossRef] [PubMed]

15. Moghaddamnia, S.; Peissig, J.; Schmitz, G.; Effenberg, A.O. A simplified approach for autonomous quality assessment of cyclic movements. In Proceedings of the 2013 18th International Conference on Digital Signal Processing (DSP), Santorini, Greece, 1-3 July 2013; IEEE: Santorini, Greece, 2013; pp. 1-5.

16. Dubus, G. Evaluation of four models for the sonification of elite rowing. J. Multimodal User Interfaces 2012, 5, 143-156. [CrossRef]

17. Atallah, L.; Leong, J.J.H.; Lo, B.; Yang, G.-Z. Energy expenditure prediction using a miniaturized ear-worn sensor. Med. Sci. Sports Exerc. 2011, 43, 1369-1377. [CrossRef] [PubMed]

18. Llosa, J.; Vilajosana, I.; Vilajosana, X.; Navarro, N.; Suriñach, E.; Marquès, J. REMOTE, a Wireless Sensor Network Based System to Monitor Rowing Performance. Sensors 2009, 9, 7069-7082. [CrossRef]

19. James, D.A.; Davey, N.; Rice, T. An accelerometer based sensor platform for insitu elite athlete performance analysis. In Proceedings of the IEEE Sensors, Vienna, Austria, 24-27 October 2004; IEEE: Vienna, Austria, 2004; pp. 1373-1376.

20. Lintmeijer, L.L.; Faber, G.S.; Kruk, H.R.; van Soest, A.J.K.; Hofmijster, M.J. An accurate estimation of the horizontal acceleration of a rower's centre of mass using inertial sensors: A validation. Eur. J. Sport Sci. 2018, 18, 940-946. [CrossRef]

21. Tessendorf, B.; Gravenhorst, F.; Arnrich, B.; Troster, G. An IMU-based sensor network to continuously monitor rowing technique on the water. In Proceedings of the 2011 Seventh International Conference on Intelligent Sensors, Sensor Networks and Information Processing, Adelaide, Australia, 6-9 December 2011; IEEE: Adelaide, Australia, 2011; pp. 253-258.

22. Bosch, S.; Shoaib, M.; Geerlings, S.; Buit, L.; Meratnia, N.; Havinga, P. Analysis of indoor rowing motion using wearable inertial sensors. In Proceedings of the 10th EAI International Conference on Body Area Networks, Sydney, Australia, 28-30 September 2015; ICST: Sydney, Australia, 2015.

23. Cesarini, D.; Lelli, G.; Avvenuti, M. Are we synchronized? Measure synchrony in team sports using a network of wireless accelerometers. In Proceedings of the 2014 International Workshop on Web Intelligence and Smart Sensing-IWWISS'14, Saint Etienne, France, 1-2 September 2014; ACM Press: Saint Etienne, France, 2014; pp. 1-6.

24. Tukiran, Z.; Ahmad, A. Exploiting LabVIEW FPGA in implementation of real-time sensor data acquisition for rowing monitoring dystem. In Recent Advances on Soft Computing and Data Mining; Ghazali, R., Deris, M.M., Nawi, N.M., Abawajy, J.H., Eds.; Springer: Cham, Switzerland, 2018; Volume 700, pp. $272-281$. ISBN 978-3-319-72549-9.

25. Groh, B.H.; Reinfelder, S.J.; Streicher, M.N.; Taraben, A.; Eskofier, B.M. Movement prediction in rowing using a Dynamic Time Warping based stroke detection. In Proceedings of the 2014 IEEE Ninth International Conference on Intelligent Sensors, Sensor Networks and Information Processing (ISSNIP), Singapore, 21-24 April 2014; IEEE: Singapore, 2014; pp. 1-6.

26. Gomes, B.B.; Ramos, N.V.; Conceição, F.A.V.; Sanders, R.H.; Vaz, M.A.P.; Vilas-Boas, J.P. Paddling force profiles at different stroke rates in elite sprint kayaking. J. Appl. Biomech. 2015, 31, 258-263. [CrossRef]

27. Cuijpers, L.S.; Passos, P.J.M.; Murgia, A.; Hoogerheide, A.; Lemmink, K.A.P.M.; de Poel, H.J. Rocking the boat: Does perfect rowing crew synchronization reduce detrimental boat movements? Scand. J. Med. Sci. Sports 2017, 27, 1697-1704. [CrossRef]

28. Dow, D.; Andrews, R.; Garcia, A.; Dryer, B.; Bonney, S. Rowing training system for on-the-water rehabiliation and sport. In Proceedings of the 8th International Conference on Body Area Networks, Boston, MA, USA, 30 September-2 October 2013; ACM: Boston, MA, USA, 2013.

29. Formaggia, L.; Mola, A.; Parolini, N.; Pischiutta, M. A three-dimensional model for the dynamics and hydrodynamics of rowing boats. Proc. Inst. Mech. Eng. Part P J. Sports Eng. Technol. 2009, 224, 51-61. [CrossRef]

30. Day, A.H.; Campbell, I.; Clelland, D.; Cichowicz, J. An experimental study of unsteady hydrodynamics of a single scull. Proc. Inst. Mech. Eng. Part M J. Eng. Marit. Environ. 2011, 225, 282-294. [CrossRef]

31. Kleshnev, V. Boat acceleration, temporal structure of the stroke cycle, and effectiveness in rowing. Proc. Inst. Mech. Eng. Part P J. Sports Eng. Technol. 2009, 224, 63-74. [CrossRef]

32. Schaffert, N.; Mattes, K. Influence of acoustic feedback on boat speed and crew synchronization in elite junior rowing. Int. J. Sports Sci. Coach. 2016, 11, 832-845. [CrossRef] 
33. Ruffaldi, E.; Peppoloni, L.; Filippeschi, A. Sensor fusion for complex articulated body tracking applied in rowing. Proc. Inst. Mech. Eng. Part P J. Sports Eng. Technol. 2015, 229, 92-102. [CrossRef]

34. Cesarini, D.; Schaffert, N.; Manganiello, C.; Mattes, K. AccrowLive: A multiplatform telemetry and sonification solution for rowing. Procedia Eng. 2014, 72, 273-278. [CrossRef]

35. Bifaretti, S.; Bonaiuto, V.; Federici, L.; Gabrieli, M.; Lanotte, N. E-kayak: A Wireless DAQ System for Real Time Performance Analysis. Procedia Eng. 2016, 147, 776-780. [CrossRef]

36. Morgoch, D.; Galipeau, C.; Tullis, S. Sprint canoe blade hydrodynamics-modeling and on-water measurement. Procedia Eng. 2016, 147, 299-304. [CrossRef]

37. Umek, A.; Kos, A. Wearable sensors and smart equipment for feedback in watersports. Procedia Comput. Sci. 2018, 129, 496-502. [CrossRef]

38. Cesarini, D.; Schaffert, N.; Manganiello, C.; Mattes, K.; Avvenuti, M. A Smartphone Based Sonification and Telemetry Platform for On-Water Rowing Training. In Proceedings of the International Conference on Auditory Display, Lodz, Poland, 6-10 July 2013.

39. Cloud, B.; Tarien, B.; Crawford, R.; Moore, J. Adaptive Smartphone-Based Sensor Fusion for Estimating Competitive Rowing Kinematic Metrics. Available online: https://engrxiv.org/nykuh/ (accessed on 10 October 2019).

40. Ben Si Said, K.; Ababou, N.; Ouadahi, N.; Ababou, A. Embedded wireless sensor network for rower motion tracking. In Proceedings of the 2016 8th International Conference on Modelling, Identification and Control (ICMIC), Algiers, Algeria, 15-17 November 2016; IEEE: Algiers, Algeria, 2016; pp. 932-937.

41. King, R.C.; Mcllwraith, D.G.; Lo, B.; Pansiot, J.; McGregor, A.H.; Yang, G.-Z. Body sensor networks for monitoring rowing technique. In Proceedings of the 2009 Sixth International Workshop on Wearable and Implantable Body Sensor Networks, Berkeley, CA, USA, 3-5 June 2009; IEEE: Berkeley, CA, USA, 2009; pp. 251-255.

42. Wang, Z.; Wang, J.; Zhao, H.; Yang, N.; Fortino, G. CanoeSense: Monitoring canoe sprint motion using wearable sensors. In Proceedings of the 2016 IEEE International Conference on Systems, Man and Cybernetics (SMC), Budapest, Hungary, 9-12 October 2016; IEEE: Budapest, Hungary, 2016; pp. 644-649.

43. Lintmeijer, L.L.; Hofmijster, M.J.; Schulte Fischedick, G.A.; Zijlstra, P.J.; Van Soest, A.J.K. Improved determination of mechanical power output in rowing: Experimental results. J. Sports Sci. 2018, 36, 2138-2146. [CrossRef]

44. Mpimis, A.; Gikas, V. Monitoring and evaluation of rowing performance using mobile mapping data. Arch. Fotogrametrii Kartografii Teledetekcji 2011, 22, 13.

45. Gravenhorst, F.; Thiem, C.; Tessendorf, B.; Adelsberger, R.; Strohrmann, C.; Arnrich, B.; Troster, G. Self-aligning and drift compensated rowing seat position measurment system based on accelerometers and magnetometers. Proc. Sport. 2012, 2012, 226-231.

46. Gravenhorst, F.; Muaremi, A.; Kottmann, F.; Troster, G.; Sigrist, R.; Gerig, N.; Draper, C. Strap and row: Rowing technique analysis based on inertial measurement units implemented in mobile phones. In Proceedings of the 2014 IEEE Ninth International Conference on Intelligent Sensors, Sensor Networks and Information Processing (ISSNIP), Singapore, 21-24 April 2014; IEEE: Singapore, 2014; pp. 1-6.

47. Gravenhorst, F.; Turner, T.; Draper, C.; Smith, R.M.; Troester, G. Validation of a rowing oar angle measurement system based on an inertial measurement unit. In Proceedings of the 2013 12th IEEE International Conference on Trust, Security and Privacy in Computing and Communications, Melbourne, Australia, 16-18 July 2013; IEEE: Melbourne, Australia, 2013; pp. 1412-1419.

48. Espinosa, H.G.; Shepherd, J.B.; Thiel, D.V.; Worsey, M.T.O. Anytime, anywhere! Inertial sensors monitor sports performance. IEEE Potentials 2019, 38, 11-16. [CrossRef]

49. Medal Table. Available online: http://www.worldrowing.com/events/2019-world-rowing-under-23-championships/ medals (accessed on 15 October 2019).

50. Stamm, A. Velocity and Arm Symmetry Investigations in Freestyle Swimming Using Accelerometry. Ph.D. Thesis, Griffith University, Brisbane, Australia, 2013.

51. Stamm, A.; James, D.A.; Thiel, D.V. Velocity profiling using inertial sensors for freestyle swimming. Sports Eng. 2013, 16, 1-11. [CrossRef]

52. Kleshnev, V. Biomechanics of Rowing; Crowood: Marlborough, UK, 2016; ISBN 978-1-78500-134-5.

(C) 2019 by the authors. Licensee MDPI, Basel, Switzerland. This article is an open access article distributed under the terms and conditions of the Creative Commons Attribution (CC BY) license (http://creativecommons.org/licenses/by/4.0/). 